\title{
Effects of caffeine and used coffee grounds on biological features of Aedes aegypti (Diptera, Culicidae) and their possible use in alternative control
}

\author{
Alessandra Theodoro Laranja ${ }^{1}$, Antonio José Manzatto ${ }^{2}$ and \\ Hermione Elly Melara de Campos Bicudo ${ }^{1}$ \\ ${ }^{1}$ Universidade Estadual Paulista, Departamento de Biologia, São José do Rio Preto, SP, Brazil. \\ ${ }^{2}$ Universidade Estadual Paulista, Departamento de Computação e Estatística, São José do Rio Preto, \\ SP, Brazil.
}

\begin{abstract}
Caffeine and used coffee grounds completely blocked the development of Aedes aegypti in the early stages, in treatments with the concentrations $1.0 \mathrm{mg} / \mathrm{mL}$ and $50 \mathrm{mg} / \mathrm{mL}$, respectively. More advanced stages and even adults were obtained in lower concentrations of both substances, enabling observations to be made of mortality rate, longevity and esterase patterns. The experiments involved treatments using either eggs or $3^{\text {rd }}$ instar larvae (L3), with or without the addition of fish food. Mortality rates prior to the adult stage and adult longevity were significantly different in the comparisons among treatments, in every kind of experiment, but in those using L3 larvae, their percentages were smaller. Observations of the time of larva and adult onset suggested that developmental time was also delayed in treatments with both substances. The addition of fish food increased significantly the number of adults produced in caffeine 0.2 and in the control, but in used coffee grounds, the opposite effect occurred. Longevity was apparently not affected by the addition of food, except again in coffee grounds, in which it decreased. In an attempt to detect a mechanism involved in the action of caffeine and coffee grounds, esterases (enzymes involved in the detoxification of xenobiotics) were analyzed in polyacrylamide gels of treated $4^{\text {th }}$ instar larvae (L4). In treatments with both substances, the expression of some carboxylesterases was affected, suggesting that they may be involved in the observed impairment.
\end{abstract}

Key words: Aedes aegypti, caffeine, used coffee grounds, mortality, longevity, esterases, alternative control.

Received: July 15, 2002; Accepted: June 26, 2003.

\section{Introduction}

Having been formerly eradicated, Aedes aegypti has reinvaded Brazil and other regions of the Americas, giving rise to a great deal of concern. The reason is that this mosquito is an important vector of dengue, yellow fever and dengue hemorrhagic fever (DHF) and has already produced devastating effects in many parts of the world. Brazilian public health services are carrying out campaigns aimed at encouraging people to adopt larval source reduction practices. Over the last 20 years, however, the major control method for maintaining mosquito population size within acceptable levels has been the use of insecticides. Mainly pyrethroids but also organophosphate are sprayed in town streets to kill adult mosquitoes, while larval and pupal stages are controlled by using granular organophosphorous insecticides.

Send correspondence to Alessandra Theodoro Laranja. UNESP/ IBILCE, Rua: Cristóvão Colombo 2265, Jardim Nazareth, 15054000 São José do Rio Preto, SP, Brazil. E-mail: alessa20@ hotmail.com.
The consequences for life and the environment of using insecticides are well known from data in literature (Topaktas et al., 1996; Titenko-Holland et al., 1997; Chauhan et al., 2000; Tian et al., 2000). In addition, $A$. aegypti is developing resistance to the generally used insecticides, impairing the efficiency of the control programs (Mourya et al., 1993; Thompson et al., 1993; Mazzarri and Georghiou, 1995; Macoris et al., 1995; Vaughan et al., 1998). For these reasons, in many parts of the world, there is increasing pressure to reduce insecticide use. The discovery of alternative control agents would be very important and is the objective of a number of specialist studies.

Caffeine (1, 3, 7-trimethilxantine), a component of coffee, tea and other widely consumed beverages, has been used in toxicological studies of several organisms. Results have revealed deleterious effects on the nervous system (Nehlig, 1999; Higure and Nohmi, 2002), on the sensitization of DNA to damage (MacPhee and Leyden, 1985; Pons and Muller, 1990), on the delayed entry of cells into mitosis and on other aspects of cell division (La Pena et al., 1981; 
Hepler and Bonsignore, 1990; Narayanan et al., 1997; Deplanque et al., 2000), on the development of organisms (Sehgal and Simões, 1976; Sehgal et al., 1977; Kawano and Simões, 1987; Fort et al., 1998; Castellanos and Rapoport, 2002; Burdan, 2003), on fertility (Hewavitharanage et al., 1999), and on chromatin structure (Terasaka and Niitsu, 1987), to mention but a few. Caffeine (CAF) also increased the production of chromosomal damage induced by chemicals or ionizing radiation (Timson, 1977; Targa and Rodriguez, 1982). In relation to mutagenicity, results for the same organism in literature are occasionally antagonistic (MacPhee and Leyden, 1985; Sasaki et al., 1989). In medicine, CAF has been included in several combinations of drugs for different purposes, such as an analgesic adjuvant, but side effects have been discussed (Díaz-Reval et al., 2001; Donovan and DeVane, 2001).

In studies carried out in our laboratory with Drosophila, CAF decreased mating frequency, egg-laying capacity, fertility and longevity, and increased developmental time and pre-copulation duration (Itoyama and Bicudo, 1992; Itoyama et al., 1995; 1998). These results and other data in literature suggested that CAF was a promising tool for alternative insect control and encouraged us to perform the present study in which its effects were analyzed on the biological features of $A$. aegypti. Used coffee grounds (UCG - the powder that is left after coffee has been filtered out to drink), due to their CAF content, was also used in the experiments with the aim of testing a product that could be readily accessible in regions where coffee is a popular drink.

\section{Material and Methods}

Aedes aegypti (Diptera; Culicidae) were collected locally by employees of SUCEN (Superintendência de Controle de Endemias) from rain-filled containers such as tires, cans, bottles and other usual breeding sites and raised in the Vector Laboratory of Vectors, at the Department of Biology - IBILCE-UNESP, São José do Rio Preto, SP, Brazil. Development of this mosquito (which is holometabolous) is divided into egg, larva (subdivided into L1, L2, L3 and L4), pupa and adult stages. Larvae and pupae were brought to the Laboratory at least once a month (mostly in the rainy season) and used to originate the cultures.

The mosquitoes were submitted to treatments with CAF (concentrations 2.0, 1.0, 0.5, 0.2 and $0.1 \mathrm{mg} / \mathrm{mL}$ ) and with UCG (concentrations 25, 50 and $100 \mathrm{mg} / \mathrm{mL}$ ). (For reasons of simplicity, the units of concentration will be omitted from much of the remainder of this text). Tap water was used in the preparation of the mediums and the control. The experiments were carried out with eggs or L3 larvae. In the first case, three Petri dishes (10 $\mathrm{cm}$ in diameter) were prepared per experiment, each one with 20 eggs less than 30 days old. In the experiments using larvae, a Petri dish containing eight or 15 L3 larvae (according to the available number) was prepared for each medium. In both kinds of experiment, the total volume of solution in each Petri dish was $40 \mathrm{~mL}$. Once a week, the larvae were transferred to fresh solution. In some of the tests using eggs, $10 \mathrm{mg}$ of fish food was added to each Petri dish to feed the larvae when they attained L3 stage. Fish food was also added in the experiments using larvae.

Observations were made of the effect of treatments on mortality during development, adult longevity and esterase patterns, in L4 larvae.

Esterase patterns were studied in L4 larvae submitted to electrophoresis in $8 \%$ polyacrylamide gels. This developmental stage was chosen because it expresses the greatest number of esterases in A. aegypti (Lima-Catelani, 1996; Sousa-Polezzi, 2002). To prepare the samples, L4 larvae from control, CAF 0.1 and 0.2 , and UCG 25 mediums were individually squashed. In total, 99, 100, 77 and 124 mosquitoes were analyzed, respectively. Each larva was homogenized in $25 \mu \mathrm{L}$ of the sample buffer solution prepared with $9.0 \mathrm{~mL}$ of the gel buffer solution $(18.17 \mathrm{~g}$ of $1.5 \mathrm{M}$ TRIS, $100 \mathrm{~mL}$ of distilled water, $6 \mathrm{M} \mathrm{HCl}$ for $\mathrm{pH} 8.8$ ) plus $1.0 \mathrm{~mL}$ of glycerol. After sample application $(10 \mu \mathrm{L}$ of each), the gels were submitted to electrophoresis at a constant $200 \mathrm{~V}$, using a buffer system at room temperature $\left(\sim 25^{\circ} \mathrm{C}\right)$. Average running time was $2.0 \mathrm{~h}$.

In order to identify the esterase bands, the gels were pre-incubated for $45 \mathrm{~min}$ at room temperature $\left(25^{\circ} \mathrm{C}\right)$, in $50 \mathrm{~mL} 0.1 \mathrm{M}$ sodium phosphate at $\mathrm{pH} 6.2$, following stain reaction in the dark $(1 \mathrm{~h})$ with a solution containing $0.04 \mathrm{~g}$ $\alpha$-naphthyl and $0.03 \mathrm{~g} \beta$-naphthyl acetate used as substrates, $0.12 \mathrm{~g}$ fast blue ruthenium red and $10 \mathrm{~mL}$ $\mathrm{N}$-propanol in $100 \mathrm{~mL} 0.1 \mathrm{M}$ sodium phosphate solution at pH 6.2. According to Johnson et al. (1966) and Steiner and Johnson (1973), when only $\alpha$-naphthyl acetate was hydrolyzed, the bands in the gel became black and were named $\alpha$-esterases; when only $\beta$-naphthyl acetate was hydrolyzed, the bands became red and were named $\beta$-esterases. The gels were distained during 24 to $48 \mathrm{~h}$, in a solution containing ethyl alcohol, acetic acid and water in a proportion of 2:1:8, respectively, and air dried at room temperature by using gelatin and cellophane wound slab gels, in an embroidery hoop (Ceron et al., 1992).

The staining degree of the esterase bands, which provides information on their level of activity, was evaluated by optical densitometry using image analysis (Program Global Lab Image, Data Translation). In the program, grayscale values range from 255 (absence of staining; in the present study, values close to this mean absent band) to zero (black; in the present case, values close to this indicate the strongest stained bands). Between these limits are found values for moderately and weakly stained bands or, in other words, bands with intermediate and weak activity.

Differences in the comparisons of mediums as to the production of larvae and adults were evaluated by Chisquare test for independent proportions. To test the equality 
of two proportions, the $\mathrm{Z}$ test (normal approach) was used. When the hypothesis of proportion equality was rejected, the transformation for multiple comparisons two by two was arcsen $(p)^{1 / 2}$, in degrees (Pazer and Swanson, 1972; Fleiss, 1981; Bussab and Morettin; 1985; Zar, 1999).

To evaluate longevity data, in experiments using eggs, comparisons were made by means of the nonparametric Mann Whitney test to evaluate longevity data in experiments using eggs. In the experiments using L3, the analysis of variance for comparison of means was used. When the hypothesis of proportion equality was rejected, Tukey multiple comparisons two by two of Tukey were made.

Statistical analysis for esterase pattern comparisons was the same as that used in the comparisons of larva and adult productions.

\section{Results}

\section{Effect of CAF and UCG on Aedes aegypti mortality during development}

\section{Experiments using eggs}

a. Tests with CAF at $2.0 \mathrm{mg} / \mathrm{mL}$ and $1.0 \mathrm{mg} / \mathrm{mL}$ and $U C G$ at $25 \mathrm{mg} / \mathrm{mL}$

CAF concentrations used in the first experiment were chosen on the basis of previous data in Drosophila (Itoyama and Bicudo, 1992) showing that $2.0 \mathrm{mg} / \mathrm{mL}$ of the substance is the LD50 for that organism. In the first experiment, sixty $A$. aegypti eggs were placed for development in water (control), CAF 2.0, CAF 1.0 and UCG 25. Fish food was added to the mediums.

As shown in Table 1, the number of ecloded larvae was high in water and CAF 1.0, moderate in UCG and small in CAF 2.0. Mortality between larval and adult stages was $100 \%$ in the two CAF concentrations, followed by UCG $(42 \%)$ and water $(24 \%)$. The time at onset of L2 stage was delayed nine days in CAF 1.0 when compared to the water medium. Adults were produced in water five days earlier than in UCG.

Table 1 - First experiment. Number and percentage of ecloded larvae, number of adults obtained, mortality before adult stage in percentage and time (days) at onset of each stage in the four types of tests. Sixty eggs were used in each medium. Fish food was added to them at the appropriate time. $\mathrm{W}=$ water $\mathrm{CAF}=$ caffeine; $\mathrm{UCG}=$ used coffee grounds.

\begin{tabular}{lcccl}
\hline Mediums & $\begin{array}{c}\text { Ecloded lar- } \\
\text { vae number } \\
(\%)\end{array}$ & $\begin{array}{c}\text { Number } \\
\text { of adults } \\
\text { obtained }\end{array}$ & $\begin{array}{c}\text { Mortality } \\
\text { before adult } \\
\text { stage (\%) }\end{array}$ & $\begin{array}{c}\text { Time at } \\
\text { onset (days) }\end{array}$ \\
\hline W & $51(85)$ & 39 & 24 & $\begin{array}{l}\text { L1(2) L2(4) } \\
\text { P(8) A(10) }\end{array}$ \\
CAF 1.0 & $53(88)$ & 0 & 100 & L1(3) L2(13) \\
CAF 2.0 & $13(21)$ & 0 & 100 & L1(2) \\
UCG 25 & $31(52)$ & 18 & 42 & L1(3) L2(5) \\
& & & & \\
\hline
\end{tabular}

\section{b. Tests with CAF at $0.5 \mathrm{mg} / \mathrm{mL}$ and $0.2 \mathrm{mg} / \mathrm{mL}$ and UCG at $25 \mathrm{mg} / \mathrm{mL}$}

The first experiment showed that CAF, in the LD50 for Drosophila $(2.0 \mathrm{mg} / \mathrm{mL})$, and also half of it $(1.0 \mathrm{mg} / \mathrm{mL})$ was strong enough for $100 \%$ mortality of the Aedes larvae. However, in order to study how this substance affects other features, and even to provide some basis for a future study of its action mechanisms, we would need treatment survivors. CAF 0.5 and 0.2 were tested and, on the basis of the results, they were used in the next 11 experiments using eggs. Eight of them were performed without and three with fish food (Table 2). The experiments without food were carried out in order to study $A$. aegypti developing in clean water conditions (such as water reservoirs and pitchers), a common situation in the environment.

Sixty eggs started every treatment of the 11 experiments. UCG 25 was tested in the eight experiments without food and in one with food. A total of 2,520 eggs was used in the two types of experiments.

The results were variable, but the proportion equality $\mathrm{H}_{0}$ in the comparison of data in experiments without food, as to the adults produced from 480 eggs, in each medium, was rejected $(p=0.000)$. In the comparison of mediums two by two (except for CAF 0.5 , which did not produce adults) all of them differed significantly:

Proportion: \begin{tabular}{cccc}
0.006 & 0.05 & 0.38 \\
& $\underline{\text { CAF } 0.2}$ & $\underline{\mathrm{W}}$ & $\underline{\mathrm{UCG}}$ \\
\hline
\end{tabular}

The highest production of adults occurred in UCG 25 and the lowest, in CAF 0.2.

In the three experiments with food, considered together, the proportion equality $\mathrm{H}_{0}$ of adults produced in the different mediums was also rejected $(p=0.000)$. The comparison two by two showed that UCG and CAF 0.2 did not differ significantly from each other, but differed from CAF 0.5 and $\mathrm{W}$.

\begin{tabular}{|c|c|c|c|}
\hline \multirow[t]{2}{*}{ Proportion: } & 0.02 & 0.25 & 0.29 \\
\hline & CAF 0.5 & UCG & CAF 0.2 \\
\hline
\end{tabular}

The highest production of adults occurred in the control medium and the smallest in CAF 0.5.

The comparison between the experiments without food and those with food, for the same treatments as to the production of adults showed rejection of proportion equality $\mathrm{H}_{0}$ for CAF $0.2(\mathrm{p}=0.000)$, for $\mathrm{W}(\mathrm{p}=0.000)$ and for UCG $(p=0.015)$. The number of adults in the significant comparisons showed an increase in the mediums with food, except in the UCG medium, in which it decreased.

\section{c. Tests with other UCG concentrations}

Another experiment was carried out, involving treatments with UCG at the same concentration previously used (25 mg/mL), at $50 \mathrm{mg} / \mathrm{mL}$ and $100 \mathrm{mg} / \mathrm{mL}$, and water as a control medium. These tests started with 120 eggs each, 
Table 2 - Results of experiments using eggs, without and with addition of food. Number of mosquitoes obtained in the different developmental stages. Mediums: caffeine (CAF) at $0.2 \mathrm{mg} / \mathrm{mL}$ and $0.5 \mathrm{mg} / \mathrm{mL}$, water (W; control) and used coffee grounds (UCG) at $25 \mathrm{mg} / \mathrm{mL}$. L1 to L4= larval stages; $\mathrm{P}=$ pupae; $\mathrm{A}=$ adults; - = treatment not carried out. Sixty eggs were used per treatment, in each experiment.

\begin{tabular}{|c|c|c|c|c|c|}
\hline & \multirow[b]{2}{*}{ Experiments } & \multicolumn{4}{|c|}{ Mediums } \\
\hline & & CAF 0.2 & CAF 0.5 & $\mathrm{~W}$ & UCG 25 \\
\hline \multirow[t]{9}{*}{ Without food } & I & $0 \mathrm{~A}(13 \mathrm{~L} 4)$ & $0 \mathrm{~A}(6 \mathrm{~L} 4)$ & $1 \mathrm{~A}(1 \mathrm{~F}) ;(5 \mathrm{~L} 4)$ & 20A (13M; 7F); (10L4) \\
\hline & II & $3 \mathrm{~A}(3 \mathrm{M}) ;(5 \mathrm{~L} 4)$ & $0 \mathrm{~A}(5 \mathrm{~L} 4)$ & $0 \mathrm{~A}(5 \mathrm{~L} 4)$ & $11 \mathrm{~A}(6 \mathrm{M} ; 5 \mathrm{~F}) ;(1 \mathrm{~L} 4)$ \\
\hline & III & $0 \mathrm{~A}(1 \mathrm{~L} 2)$ & $0 \mathrm{~A}(4 \mathrm{~L} 1)$ & $0 \mathrm{~A}(2 \mathrm{~L} 2)$ & 0A (4P; 7L4) \\
\hline & IV & $0 \mathrm{~A}(16 \mathrm{~L} 4)$ & $0 \mathrm{~A}(1 \mathrm{~L} 3)$ & $8 \mathrm{~A}(5 \mathrm{M} ; 3 \mathrm{~F}) ;(21 \mathrm{~L} 4)$ & 38A (17M; 21F); (8L4) \\
\hline & $\mathrm{V}$ & $0 \mathrm{~A}(2 \mathrm{~L} 4)$ & $0 \mathrm{~A}(4 \mathrm{~L} 3)$ & 2A (1M; 1F); (16L4) & $39 \mathrm{~A}(23 \mathrm{M} ; 16 \mathrm{~F})$ \\
\hline & VI & $0 \mathrm{~A}(10 \mathrm{~L} 3)$ & $0 \mathrm{~A}(6 \mathrm{~L} 3)$ & $1 \mathrm{~A}(1 \mathrm{M}) ;(11 \mathrm{~L} 4)$ & $34 \mathrm{~A}(12 \mathrm{M} ; 22 \mathrm{~F}) ;(2 \mathrm{~L} 4)$ \\
\hline & VII & $0 \mathrm{~A}(23 \mathrm{~L} 4)$ & $0 \mathrm{~A}(1 \mathrm{~L} 3)$ & 10A (5M; 5F); (19L4) & 37A (20M; 17F); (6L4) \\
\hline & VIII & $0 \mathrm{~A}(2 \mathrm{~L} 4)$ & $0 \mathrm{~A}(2 \mathrm{~L} 2)$ & $3 \mathrm{~A}(2 \mathrm{M} ; 1 \mathrm{~F})$ & 4A (3M; 1F); (1L4) \\
\hline & Total & $\begin{array}{l}72 \mathrm{~L}(15 \%) \\
3 \mathrm{~A}(0.62 \%)\end{array}$ & $29 \mathrm{~L}(6.04 \%)$ & $\begin{array}{l}79 \mathrm{~L}(16.46 \%) \\
25 \mathrm{~A}(5.21 \%)\end{array}$ & $\begin{array}{c}35 \mathrm{~L}(7.29 \%) ; 4 \mathrm{P}(0.83 \%) \\
183 \mathrm{~A}(38.12 \%)\end{array}$ \\
\hline \multirow[t]{4}{*}{ With food } & IX & 36A (18M; 18F); (10L4) & $3 \mathrm{~A}(8 \mathrm{~L} 4)$ & 50A (34M; 16F); (2L4) & - \\
\hline & $\mathrm{X}$ & 16A (10M; $6 \mathrm{~F}) ;(5 \mathrm{~L} 4)$ & $0 \mathrm{~A}(36 \mathrm{~L} 1)$ & $43 \mathrm{~A}$ & - \\
\hline & XI & $0 \mathrm{~A}(32 \mathrm{~L} 4)$ & $0 \mathrm{~A}(5 \mathrm{~L} 3)$ & 22A (12M; 10F); (26L4) & 15A (7M; 8F); (12L4) \\
\hline & Total & $\begin{array}{l}47 \mathrm{~L}(26.11 \%) \\
52 \mathrm{~A}(28.89 \%)\end{array}$ & $\begin{array}{c}\text { 49L }(27.22 \%) \\
3 \mathrm{~A}(1.67 \%)\end{array}$ & $\begin{array}{c}\text { 28L }(15.55 \%) \\
115 \mathrm{~A}(63.89 \%)\end{array}$ & $\begin{array}{l}12 \mathrm{~L}(20 \%) \\
15 \mathrm{~A}(25 \%)\end{array}$ \\
\hline
\end{tabular}

and fish food was added to the mediums. In UCG 50 and UCG 100 mediums, development stopped at L3 and L2 stages, respectively. Six adults were produced in the UCG 25 and 31 in the water.

\section{Experiments using L3 larvae}

In the light of the results, CAF 0.2 plus food was considered an appropriate medium to continue the studies.

In order to see if $A$. aegypti treatments using larvae produce different results when compared to those using eggs, three experiments were performed using L 3 larvae in treatments with CAF 0.2 and 0.1 , with UCG 25 and water for control (Table 3). Fish food was added to the mediums. A total of 152 larvae (38 per treatment) was used. In the comparison among these treatments for the number of adults produced, the proportion equality $\mathrm{H}_{0}$ was rejected

Table 3 - Results of experiments using L3 larvae (38 per experiment). Number of L4, female (F) and male (M) adults produced and mortality (in percentage), in the treatments with water (W), caffeine (CAF) at 0.1 $\mathrm{mg} / \mathrm{mL}$ and $0.2 \mathrm{mg} / \mathrm{mL}$ and used coffee grounds (UCG) at $25 \mathrm{mg} / \mathrm{mL}$. Fish food was added to the mediums.

\begin{tabular}{|c|c|c|c|c|}
\hline & \multicolumn{4}{|c|}{ Mediums } \\
\hline & W & CAF 0.1 & CAF 0.2 & UCG 25 \\
\hline L4 & 3 & 10 & 20 & 4 \\
\hline $\mathrm{F}$ & 19 & 15 & 4 & 10 \\
\hline M & 15 & 13 & 7 & 11 \\
\hline Total & $\begin{array}{c}3 \mathrm{~L}(7.89 \%) \\
34 \mathrm{~A}(89.48 \%)\end{array}$ & $\begin{array}{l}\text { 10L }(26.31 \%) \\
28 \mathrm{~A}(73.68 \%)\end{array}$ & $\begin{array}{l}20 \mathrm{~L}(52.63 \%) \\
11 \mathrm{~A}(28.94 \%)\end{array}$ & $\begin{array}{c}4 \mathrm{~L}(10.53 \%) \\
21 \mathrm{~A}(55.26 \%)\end{array}$ \\
\hline $\begin{array}{l}\text { Mortal- } \\
\text { ity (\%) }\end{array}$ & 10.52 & 26.32 & 71.06 & 44.74 \\
\hline
\end{tabular}

$(\mathrm{p}=0.000)$. In this case, production in $\mathrm{W}$ differed from that in CAF 0.2 and UCG:

\begin{tabular}{ccccc} 
Proportion: & 0.29 & 0.55 & 0.74 & 0.89 \\
& CAF 0.2 & UCG & CAF 0.1 & W \\
\hline
\end{tabular}

Males and females were produced in ratios close to 1:1 in these experiments and in those using eggs.

Comparisons of the same treatments between experiments using eggs plus food (Table 2) and those using larvae also with addition of food (Table 3) were made as to the adults produced. In the case of the CAF 0.2 medium, the proportion equality $\mathrm{H}_{0}$ was accepted for experiments using eggs plus food and for those using L3 plus food $(p=0.9942)$. However, in the case of the UCG medium, the two types of experiment differed significantly. The proportion equality $\mathrm{H}_{0}$ was rejected at $\mathrm{p}=0.0025$. The experiments using L3 plus food produced a greater number of adults than those using eggs plus food. In the $\mathrm{W}$ medium, the two types of experiment also differed significantly $(\mathrm{p}=$ 0.0059 ). In this case L3 plus food also produced the greatest percentage of adults.

\section{Tests with UCG in a greenhouse}

After the experiments performed in the laboratory suggesting that UCG at concentrations of about $50 \mathrm{mg} / \mathrm{mL}$ could be an auxiliary agent in the alternative control of $A$. aegypti at the larval stage, a series of experiments was carried out in a greenhouse. UCG in a concentration of four level tablespoons per glass of water (about $200 \mathrm{mg} / \mathrm{mL}$, an excessive concentration for security) and only water were 
placed in 12 and seven plant pot saucers, respectively. Fish food was not added to the mediums. A total of 480 and 180 Aedes eggs was distributed among saucers in the two kinds of mediums, respectively. In the UCG treated plant pot saucers, development stopped at stage L3. In the seven control plant pots saucers, development continued till adult stage. In order to avoid release of mosquitoes in the greenhouse, L4 larvae from the control saucers were transferred to cages in the laboratory where they completed development. Fifty adults from the original 180 eggs were obtained in the control saucers $(27.8 \%)$. L3 larvae were produced in the treated plant pots on the seventh day after the start of the experiments, and in the control, on the fourth day.

\section{Adult longevity}

Longevity was computed for adult males and females produced in tests using eggs, in mediums with UCG 25 and with water, with and without food (Table 4). The comparisons of mean female longevity, in UCG with and without food, versus water with and without food, showed significant difference only for UCG with food versus water with food $(p=0.0002)$. In this case, female longevity in UCG with food was lower. For males, no comparison showed any significant difference in longevity.

Longevity was also computed for adults produced in the treatments using L3, including water, CAF 0.1, CAF 0.2 and UCG 25 , in every case with the addition of food. The statistical analysis was carried out for males and females together. The comparisons among the four mediums showed

Table 4 - Descriptive statistics for longevity data of adults from experiments using eggs, with and without addition of food (f), developed in mediums with used coffee grounds (UCG) at $25 \mathrm{mg} / \mathrm{mL}$ and water (W), and from experiments using L3 larvae plus food, developed in mediums with caffeine (CAF) at 0.1 and $0.2 \mathrm{mg} / \mathrm{mL}, \mathrm{UCG}$ at $25 \mathrm{mg} / \mathrm{mL}$ and water. $\mathrm{F}=$ females; $\mathrm{M}=$ males; $\mathrm{N}=$ number of adults.

\begin{tabular}{|c|c|c|c|c|c|}
\hline Experiments & Mediums & Sex & $\mathrm{N}$ & Mean $\pm \mathrm{SE}$ & Median \\
\hline \multirow[t]{12}{*}{ Eggs } & UCG & $\mathrm{F}$ & 86 & $35.6 \pm 3.9$ & 25.5 \\
\hline & & M & 94 & $13.2 \pm 2.0$ & 7.0 \\
\hline & & Total & 180 & $24.3 \pm 2.3$ & 9.0 \\
\hline & $\mathrm{UCG}+\mathrm{f}$ & $\mathrm{F}$ & 20 & $17.1 \pm 5.7$ & 12.0 \\
\hline & & M & 13 & $18.1 \pm 7.6$ & 5.0 \\
\hline & & Total & 33 & $17.0 \pm 4.4$ & 7.5 \\
\hline & W & F & 11 & $37.9 \pm 8.2$ & 36.0 \\
\hline & & M & 14 & $23.4 \pm 5.7$ & 23.0 \\
\hline & & Total & 25 & $29.8 \pm 4.9$ & 29.0 \\
\hline & $W+f$ & $\mathrm{~F}$ & 29 & $47.8 \pm 5.2$ & 52.0 \\
\hline & & M & 31 & $18.7 \pm 2.0$ & 22.0 \\
\hline & & Total & 58 & $33.8 \pm 3.3$ & 25.0 \\
\hline \multirow[t]{4}{*}{ L3 } & $\mathrm{CAF}(0.1)+\mathrm{f}$ & Total & 28 & $18.5 \pm 4.1$ & 13.5 \\
\hline & $\mathrm{CAF}(0.2)+\mathrm{f}$ & Total & 11 & $34.9 \pm 9.4$ & 26.0 \\
\hline & $\mathrm{UCG}+\mathrm{f}$ & Total & 21 & $37.9 \pm 6.7$ & 34.0 \\
\hline & $W+f$ & Total & 33 & $54.2 \pm 4.9$ & 63.0 \\
\hline
\end{tabular}

that mean longevity in CAF 0.1 did not differ from that in CAF 0.2, but in CAF 0.1 it was significantly lower than that in $\mathrm{W}$ and $\mathrm{UCG}$; UCG, W and CAF 0.2 did not differ as to this feature, as follows:

(Mean longevity equality $\mathrm{H}_{0}$ rejected; $\mathrm{p}=0.000$ )

\begin{tabular}{ccccc} 
Means: & 18.50 & 34.9 & 37.9 & 54.2 \\
& CAF 0.1 & CAF 0.2 & UCG 25 & W \\
\cline { 1 - 2 } & & & &
\end{tabular}

Comparison of mean adult longevity in UCG 25 and $\mathrm{W}$ mediums, among the three types of experiment (using eggs with and without food and using larvae) produced the results below.

For UCG mediums:

(Mean longevity equality $\mathrm{H}_{0}$ rejected; $\mathrm{p}<0.05$ )

\begin{tabular}{cccc} 
Means: & 17.0 & 24.3 & 37.9 \\
& eggs -UCG + food & eggs-UCG & L3-UCG + food \\
\hline &
\end{tabular}

Mean adult longevity in UCG was significantly greater in the experiments using larvae than in those using eggs plus food. duced:

The same comparison for the water medium pro-

(Mean longevity equality $\mathrm{H}_{0}$ rejected; $\mathrm{p}=0.000$ )

Means:

\begin{tabular}{|c|c|c|}
\hline 29.8 & 33.8 & 54.2 \\
\hline eggs-W & eggs-W + food & L3-W + food \\
\hline
\end{tabular}

In this case, mean adult longevity in experiments using larvae was significantly greater than in experiments using eggs with or without food.

\section{Esterase patterns of CAF and UCG treated mosquitoes}

Five esterase bands were apparently affected in L4 larvae submitted to treatments with CAF and UCG from the egg stage onwards, in both cases with the addition of food. Following the numbering adopted by Lima-Catelani (1996) to designate $A$. aegypti esterase bands, they are: EST-1, EST-3, EST-7, EST-19 and EST-20 (Figure 1).

The treatments were compared for the frequency of larvae expressing or not the bands and, for those expressing them, for the activity degree based on their staining intensity and thickness, in the gels. The percentages of larvae that showed each of those esterase bands, in every treatment and control, are shown in Table 5. For larvae which showed the bands, three activity degrees were subjectively differentiated and designated, in increasing order,,+++ and +++ . In order to better characterize these subjective classes, they were submitted to an image analysis program, which evaluates the staining intensity of the bands in grayscale values. For bands which we classified as presenting the greatest degree of activity $(+++)$ grayscale values varied from five to 100 , for bands from the intermediate class (++), from 120 to 200 , and for bands with the lowest 


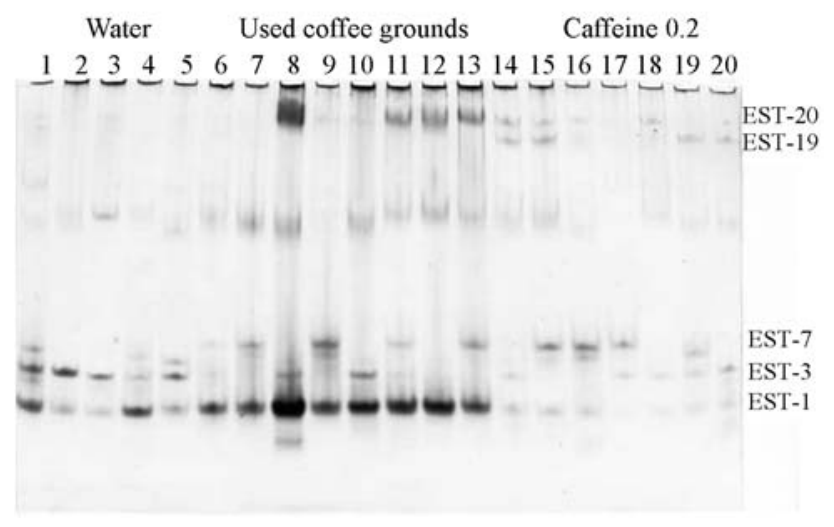

Figure 1 - Polyacrylamide gel with the esterase bands of A. aegypti (L4 stage) that showed expression variation in different mediums: control (columns 1 to 5), used coffee grounds at $25 \mathrm{mg} / \mathrm{mL}$ (columns 6 to 13) and caffeine at $0.2 \mathrm{mg} / \mathrm{mL}$ (columns 14 to 20 ).

degree of activity (+), from 220 to 246 . The absence of the band in the gel was set at about 250 on the grayscale. The scale values absent in the class intervals were not found in the measurements. The profile graphs corresponding to the band patterns are shown in Figures 1 and 2. The horizontal axis of the profile graph represents the points along the line segment (horizontal sequence of bands in the gel) and the vertical axis represents the grayscale value at each point (in each band).

Comparisons among mediums for the frequencies of larvae not expressing each of the five esterase bands (NE column in the Table 5) showed significant differences for EST-1 $\left(\chi_{\text {obs. }}^{2}=9.42\right)$ and EST-20 $\left(\chi_{\text {obs. }}^{2}=36.86\right)$ $\left(\chi_{\text {critic }}^{2}=7.81 ; p<0.05\right)$. Table 6 shows the results of two by two multiple comparisons of the mediums for these two bands. Values obtained for treatment differences (MSD Minimum Significant Difference, $\mathrm{z}=1.96, \mathrm{p}<0.05$ ) showed that the frequency of L4 that did not express esterase EST-1 was significantly greater in the treatment with CAF 0.2 , in comparison with the other three mediums, but the other treatments did not differ statistically from each other (CAF $0.2>$ CAF $0.1=\mathrm{W}=\mathrm{UCG})$.

The frequency of L4 that did not express the band EST- 20 was greatest in CAF 0.1, smallest in UCG, and did not differ between $\mathrm{W}$ and $\mathrm{CAF} 0.2(\mathrm{CAF} 0.1>\mathrm{W}=\mathrm{CAF}$ $0.2>\mathrm{UCG})$.

Because of the sample sizes, the comparison of bands for the degrees of activity in the different mediums had to be made between the class +++ plus the class ++ versus the class + . Significant differences were observed for bands

Table 5 - Percentage of larvae expressing the esterase bands (TE), in the different degrees $(+++,++,+$ ) or not expressing them (NE), in the treatments with caffeine (CAF) at 0.1 and $0.2 \mathrm{mg} / \mathrm{mL}$, used coffee grounds (UCG) at $25 \mathrm{mg} / \mathrm{mL}$ and water (W) for control. $\mathrm{N}=$ number of larvae analyzed for the band activity degrees.

\begin{tabular}{|c|c|c|c|c|c|c|c|}
\hline \multirow[b]{2}{*}{ Bands } & \multirow[b]{2}{*}{ Mediums } & \multirow[b]{2}{*}{$\mathrm{N}$} & \multicolumn{5}{|c|}{ Degrees of esterase activity (\%) } \\
\hline & & & TE & +++ & ++ & + & $\mathrm{NE}$ \\
\hline \multirow[t]{4}{*}{ EST-1 } & $\mathrm{W}$ & 99 & 89.90 & 4.05 & 32.32 & 53.53 & 10.10 \\
\hline & UCG & 124 & 86.29 & 27.42 & 25.00 & 33.87 & 13.71 \\
\hline & CAF 0.1 & 100 & 86.00 & 1.00 & 2.00 & 83.00 & 14.00 \\
\hline & CAF 0.2 & 77 & 74.04 & 2.60 & 10.40 & 61.04 & 25.96 \\
\hline \multirow[t]{4}{*}{ EST-3 } & $\mathrm{W}$ & 99 & 79.80 & 28.28 & 26.27 & 25.25 & 20.20 \\
\hline & UCG & 124 & 70.97 & - & 7.26 & 63.71 & 29.03 \\
\hline & CAF 0.1 & 100 & 68.00 & 7.00 & 43.00 & 18.00 & 32.00 \\
\hline & CAF 0.2 & 77 & 62.34 & 12.99 & 25.97 & 23.38 & 37.66 \\
\hline \multirow[t]{4}{*}{ EST-7 } & $\mathrm{W}$ & 99 & 65.66 & 22.23 & 26.26 & 17.17 & 34.34 \\
\hline & UCG & 124 & 62.92 & 1.61 & 13.71 & 47.60 & 37.08 \\
\hline & CAF 0.1 & 100 & 76.00 & 16.00 & 42.00 & 18.00 & 24.00 \\
\hline & CAF 0.2 & 77 & 72.73 & 19.48 & 33.77 & 19.48 & 27.27 \\
\hline \multirow[t]{4}{*}{ EST-19 } & W & 99 & 12.13 & - & - & 12.13 & 87.87 \\
\hline & UCG & 124 & 16.94 & - & 2.42 & 14.52 & 83.06 \\
\hline & CAF 0.1 & 100 & 8.00 & - & 2.00 & 6.00 & 92.00 \\
\hline & CAF 0.2 & 77 & 10.39 & - & - & 10.39 & 89.61 \\
\hline \multirow[t]{4}{*}{ EST-20 } & W & 99 & 13.13 & - & 3.03 & 10.10 & 86.87 \\
\hline & UCG & 124 & 32.26 & 0.81 & 9.67 & 21.78 & 67.74 \\
\hline & CAF 0.1 & 100 & 2.00 & - & 1.00 & 1.00 & 98.00 \\
\hline & CAF 0.2 & 77 & 15.60 & - & - & 15.60 & 84.40 \\
\hline
\end{tabular}




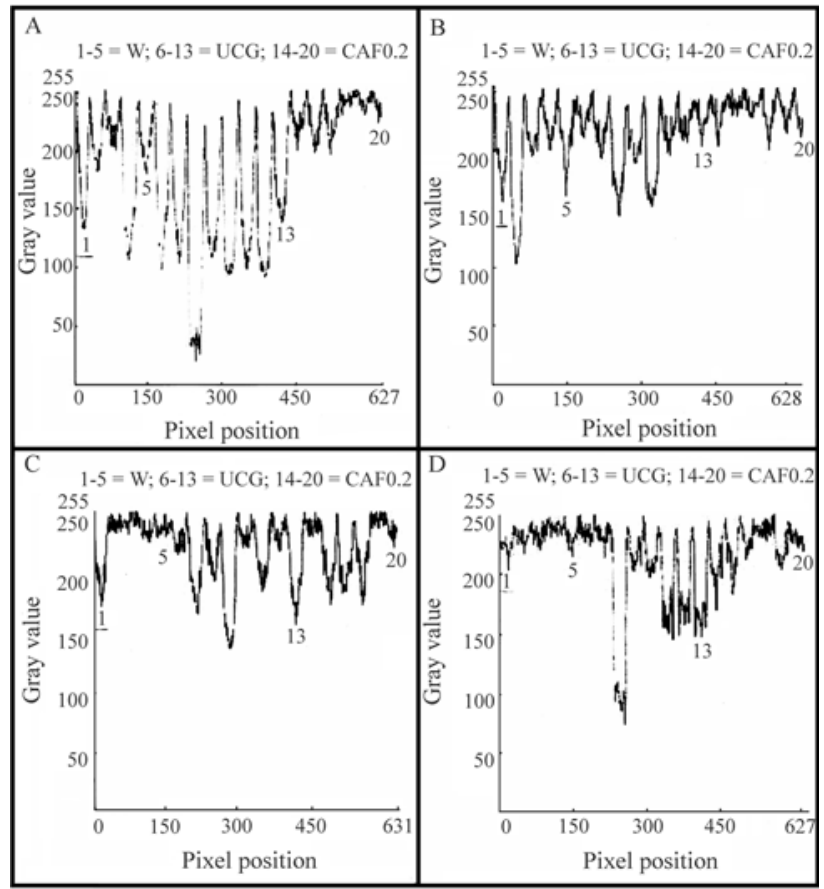

Figure 2A-D - Profile graphs for expression variation of the esterase bands with significant differences among treatments, shown in Figure 1. $\mathrm{A}=\mathrm{EST}-1, \mathrm{~B}=\mathrm{EST}-3, \mathrm{C}=\mathrm{EST}-7, \mathrm{D}=\mathrm{EST}-20$. Samples and grayscale values are on the horizontal and vertical axis, respectively.

EST-1 $\left(\chi_{\text {obs. }}^{2}=77.59\right)$, EST-3 $\left(\chi_{\text {obs. }}^{2}=85.44\right)$ and EST-7 $\left(\chi_{\text {obs. }}^{2}=59.53\right) ;\left(\chi_{\text {critic }}^{2}=7.81 ; \mathrm{p}<0.05\right)$. The band EST-20 was not examined because of its low frequency.

In the two by two multiple comparisons (Table 6), differences in the degree of activity of band EST-1 were significant for all mediums, followed for class + , the sequence of proportions: CAF $0.1>\mathrm{CAF} 0.2>\mathrm{W}>\mathrm{UCG}$. For bands EST-3 and EST-7, only the medium UCG (which showed the greatest frequency of larvae with the lowest esterase activity) produced significant differences in comparison with the other three mediums. Thus, UCG $>$ CAF $0.2=\mathrm{CAF} 0.1=\mathrm{W}$. No comparison involving EST-19 was significant.

\section{Discussion}

Our ability to control the mosquito A. aegypti and, consequently, to prevent the epidemic diseases which it transmits, is still very poor and is largely based on the use of organophosphorous insecticides. In the present study, aiming to contribute to the knowledge of substances which might be used in alternative control and which could be less harmful to humans and the environment than the usual insecticides, caffeine and (secondarily) used coffee grounds were analyzed for their effects on the mortality of this mosquito.

The possibility of affecting development, blocking it before the adult stage, is a basic requirement for any substance being considered for use in the alternative control of A. aegypti. The reason is that the disease viruses are transmitted by adult female bites, since they need to feed on blood in order to ensure oocyte maturation. CAF, tested in the present study, affected development, killing the mosquitoes before reaching the adult stage. The greater the concentration of CAF in the medium the earlier in larval development the blockade occurred. Of the concentrations used, $2.0 \mathrm{mg} / \mathrm{mL}$ produced the strongest effect, killing $100 \%$ of the larvae in the L1 sub-phase. At $1.0 \mathrm{mg} / \mathrm{mL}$, development was blocked at L2, while in most treatments with CAF $0.5 \mathrm{mg} / \mathrm{mL}$, mosquitoes died in the L 3 stage or, at the latest, in L4. In treatments with mediums containing CAF $0.2 \mathrm{mg} / \mathrm{mL}$, the production of a small number of adults (three at most) predominated.

In the CAF 0.2 medium, the addition of food improved mosquito development significantly, increasing the number of adults produced in the treatment as much as 10 -fold. In water (control), the improvement by food addition was even greater. As mentioned, the experiments without food were carried out in order to study $A$. aegypti in water considered "clean", such as that in water reservoirs and pitchers where these mosquitoes are frequently found in the domestic environment. In these breeding sites, they eat particles, bacteria and the carcasses of dead larvae and the molts produced during development, at stage changes.

In the light of the present results, we can state that CAF affected the larvae, provoking mortality before the

Table 6 - Two by two multiple comparisons of proportions, for frequencies of L4 not expressing the bands EST-1 and EST-20 and for activity degree of bands EST-1, EST-3 and EST-7, $\mathrm{p} \leq 0.05 . \mathrm{W}=$ water; $\mathrm{UCG}=$ used coffee grounds at $25 \mathrm{mg} / \mathrm{mL} ; \mathrm{CAF} 0.1=$ caffeine at $0.1 \mathrm{mg} / \mathrm{mL} ; \mathrm{CAF} 0.2=$ caffeine at $0.2 \mathrm{mg} / \mathrm{mL}$.

\begin{tabular}{lllllll}
\hline & \multicolumn{2}{c}{ For the frequency of L4 without bands } & & \multicolumn{3}{c}{ For the activity degree of bands } \\
\cline { 2 - 3 } \cline { 5 - 6 } Comparisons & EST-1 & EST-20 & & EST-1 & EST-3 & EST-7 \\
\hline UCG x W & 0.92 & $3.56^{*}$ & & $2.86^{*}$ & $9.66^{*}$ & $7.14^{*}$ \\
UCG x CAF 0.1 & 0 & $6.80^{*}$ & & $11.40^{*}$ & $10.70^{*}$ & $7.43^{*}$ \\
UCG x CAF 0.2 & $2.04^{*}$ & $2.71^{*}$ & & $6.14^{*}$ & $6.97^{*}$ & $6.50^{*}$ \\
W x CAF 0.1 & 0.87 & $3.05^{*}$ & & $7.40^{*}$ & 0.86 & 0.28 \\
W x CAF 0.2 & $2.76^{*}$ & 0.56 & & $3.28^{*}$ & 0.62 & 0.12 \\
CAF 0.1 x CAF 0.2 & $1.97^{*}$ & $3.18^{*}$ & & $2.80^{*}$ & 1.26 & 0.37 \\
\hline
\end{tabular}


adult stage in a dose-dependent way, that is, the greater the CAF concentration, the earlier the development was interrupted. A small number of adults began to be produced in mediums with CAF 0.5, and a greater number of adults at 0.2 , when food was added to both mediums. Data in the literature has already shown dose-dependent harmful effects of CAF in other organisms. Bertrand et al. (1965, apud Timson, 1977) described a dose-dependent effect in ecthrodactily production in the progeny of treated pregnant rats. In Drosophila, a significant decrease in progeny productivity, longevity and egg laying capacity has been shown to be dependent on increased CAF concentration in the culture medium (Itoyama and Bicudo, 1992; Itoyama et al., 1998). A dose-dependent interaction between CAF and ethanol in promoting ethanol-induced aversion has also been described (Kunin et al., 2001).

Thus the present results showed that, in the laboratory, CAF at $1.0 \mathrm{mg} / \mathrm{mL}$ is a promising concentration for alternative Aedes control at the larval stage. However, in order to obtain information related to the effect of caffeine on other biological features, the concentration $0.2 \mathrm{mg} / \mathrm{mL}$ plus food is appropriate because, in this medium, a high number of L4 larvae (the best larval instar for manipulation in the laboratory), and a moderate number of adults are produced, becoming available for study. We consider that in the conditions of our experiments, this caffeine concentration is closest to the LD50 for A. aegypti.

The UCG also affected the development of $A$. aegypti. In treatments with 50 and $100 \mathrm{mg} / \mathrm{mL}$ concentrations, development was blocked at L3 and L2, respectively, in which the larvae died. Thus, in these concentrations, UCG is promising for alternative control. In tests with eggs in a greenhouse, using four level tablespoons per $200 \mathrm{~mL}$ of water, in plant pot saucers, development of the mosquitoes stopped at the L3 stage, at which they died. However, to enable biological features to be analyzed, the $25 \mathrm{mg} / \mathrm{mL}$ concentration is indicated. In this concentration, in the absence of food, the UCG medium produced more adults than the control. The UCG composition includes aminoacids, essential oils and other components some of which may be responsible for these results. Tango (1971) considered UCG a very poor source of aminoacids because they only represent about $12 \%$ of the dry matter and half of the essential aminoacids are absent. However, at very low concentrations of UCG, some of these components could "feed" the Aedes, overcoming, at least partially, the harmful effects. In addition to CAF, other anti-physiological components present in UCG are tannins, chlorogenic acid, caffeic acid and potassium in excess (Brenes, 1979). Under the effect of $\mathrm{CAF}$ and $\mathrm{UCG}$, the mosquitoes frequently remain for a long time in the larval stage before death.

It is interesting that, in the case of UCG, the addition of food had the opposite effect to that observed in CAF and the control: the number of adults decreased. An explanation for such a reduction might be the increased deterioration of the medium by the fish food. Longevity, however, was not significantly affected by the addition of food, either in UCG or in water. But female longevity in water plus food was greater than in UCG plus food.

In experiments in which the treatments used L3 larvae plus food instead of eggs, the impairment effect of CAF and UCG on the production of adults was significant in comparison with the control. However, the comparison between experiments using eggs plus food and those using L3 plus food did not show any significant increase in the production of adults in CAF 0.2, but increased in UCG and water treatments using larvae. This may indicate that the stress caused by treatment before the L3 stage increases mosquitoe mortality in UCG and water, but not in CAF. This may be of interest when considering $\mathrm{CAF}$ as an alternative control agent; it impairs development similarly no matter the stage, from egg to L3.

Longevity was also less affected in experiments using L3 larvae than in those using eggs plus food, in the UCG and water mediums, but the comparisons among CAF 0.2, UCG and water treatments showed no significant decrease in adult longevity in experiments using L3 larvae. However, the mean longevities showed a difference of 20 days between water and CAF 0.2 and a difference of 16 days between water and UCG. Such statistically insignificant differences are highly meaningful in biological terms, especially for females, which under the effect of both substances, would have a shorter lifespan and consequently a shorter time to bite and transmit diseases.

Some observations of the onset of stages in different treatments suggested that the developmental time of $A$. aegypti is delayed by CAF and UCG. For example, in the first experiment in comparison with the water medium, delays of nine days in L2 production, in CAF, and five days in adult production, in UCG, were observed. In the UCG tests carried out in the greenhouse, treated larvae attained L3 instar three days after the observation of the same stage in the control plant pot saucers. Other observations reinforced the suggestion. Developmental delay due to caffeine intake has also been observed in other organisms such as the Diptera Telmatoscopus albipunctatus (Sehgal et al., 1977) and Drosophila prosaltans (Itoyama and Bicudo, 1992), the mollusk Biomphalaria glabrata (Kawano and Simões, 1987), and rats (Pollard et al., 1987). Data in Drosophila prosaltans (Itoyama et al., 1997) suggested that caffeine treatment increases the duration of the cell division process. According to these authors, this could be a reason for the increase in developmental time.

In an attempt to identify the mechanism by which CAF and UCG affect the biological features of Aedes, the esterase patterns of larvae submitted to treatments and the control were analyzed. Esterases are enzymes involved in several important physiological processes in organisms, including reproduction, digestion, metabolism of juvenile hormone metabolism and detoxification of xenobiotics 
(Mane et al., 1983; Jones and Bancroft, 1986; PerezMendoza et al., 2000; Shanmugavelu et al., 2000). Studies carried out in our laboratory showed that in A. aegypti resistant to organophosphorous insecticide, the synthesis of some esterases is increased (Lima-Catelani, 1996; Sousa-Polezzi, 2002). The importance of esterases in biological processes is reinforced by the fact that their expression is submitted to regulatory control in development and also in different tissues (Lima-Catelani, 1996; Andrews et al., 2000; Arbeitman et al., 2002).

The expression of four esterase bands was significantly affected in larvae treated with CAF and UCG. In CAF, expression of esterase EST-1 decreased, most of the larvae failing to express the band or expressing it in the lowest degree. In UCG, the effects were different. Expression of EST-1 increased (++ plus +++ levels predominated). The expression of EST-20 also increased in UCG, while expression of EST-3 and EST-7 decreased.

EST-1, EST-3 and EST-7 were classified by LimaCatelani (1996) as $\alpha$-esterases, and EST-20 as $\beta$-esterase. EST-1 is a very important enzyme in A. aegypti. It was observed in $100 \%$ of mosquitoes at every stage and it is also the esterase band with the greatest thickness and the highest staining degree, mainly in L4, pupae and adults, denoting that it is produced at a high level (Lima-Catelani, 1996; Sousa-Polezzi, 2002). Although the function of this band is not yet known, its partial or complete blockage in CAF treatment might be playing an important role in the harmful effects detected in $A$. aegypti. In UCG the expression of EST-1 and EST-20 increased. But in this medium, the EST-3 and EST-7 bands had their expression decreased, and this might be affecting biological features. Thus, although UCG was initially included in the tests because of its caffeine content (about 1.12 to $1.34 \%$ in the seed, depending on the Coffea arabica strain, according to Tango, 1971), our observations suggest that other components of the UCG are affecting the mosquitoes.

Lima-Catelani (1996) classified EST-1, EST-3, EST-7 and EST-20 as carboxylesterases. The group of carboxylesterases includes enzymes involved in insecticide degradation, their increased activity being the main mechanism in organophosphorous resistance, in several organisms (Vaughan and Hemingway, 1995; Vaughan et al., 1997). In Aedes aegytpti, the same process seems to occur (Lima-Catelani, 1996). The present data suggest that such enzymes are also involved in the response to stress provoked by CAF and UCG, pointing to a mechanism at least partially common in both cases. The study of the subject deserves continuation.

\section{Acknowledgments}

Thanks are due to CAPES (Coordenadoria de Aperfeiçoamento de Pessoal de Ensino Superior) for a fellowship given to A.T.L, to SUCEN (Superintendência de
Controle de Endemias) of São José do Rio Preto, for providing mosquitoes, to the Zoology and Botany Department of IBILCE for providing the mice for feeding the mosquitoes, and to Dr. Peter James Harris for the English language revision of this article.

\section{References}

Andrews J, Bouffard GG, Cheadle C, Lii J, Becker KG and Oliver B (2000) Gene discovery using computational and microarray analysis of transcription in the Drosophila melanogaster testes. Genome Res 10:2030-2043.

Arbeitman MN, Furlong EEM, Imam F, Johnson E, Null BH, Baker BS, Krasnow MA, Scott MP, Dans RW and White KP (2002) Gene expression during the life cycle of Drosophila melanogaster. Science 297:2270-2275.

Brenes RAG (1979) Processing of coffee pulp: chemical treatments. In: Coffee pulp - Composition, technology, and utilization. Institute of Nutrition of Central America and Panama, pp 72-81.

Burdan F (2003) Intrauterine growth retardation and lack of teratogenic effects of prenatal exposure to the combination of paracetamol and caffeine in Wistar rats. Reprod Toxicol 17:51-58.

Bussab WO and Morettin PA (1985) Estatística básica. 3rd edition. Atual Editora, São Paulo, 321 pp.

Castellanos FX and Rapoport JL (2002) Effects of caffeine on development and behavior in infancy and childhood: a review of the published literature. Food Chem Toxicol 40:1235-1242.

Ceron CR, Santos JR and Bicudo HEMC (1992) The use of gelatin to dry cellophane wound slab gels in an embroidering hoop. Rev Bras Genet 15(1):201-203.

Chauhan LK, Pant N, Gupta SK and Srivastava SP (2000) Induction of chromosome aberrations, micronucleus formation and sperm abnormalities in mouse following carbofuran exposure. Mutat Res 465(1-2):123-129.

Deplanque G, Vincent F, Mah-Becherel MCM, Cazenave J-P, Bergerat J-P and Klein-Soyer C (2000) Caffeine does not cause override of the G2/M block induced by Uvc or gamma radiation in normal human skin fibroblasts. Br $\mathrm{J}$ Cancer 83(3):346-353.

Díaz-Reval I, Ventura-Martínez R, Hernández-Delgadillo GP, Domínguez-Ramírez AM and López-Muñoz FJ (2001) Effect of caffeine on antinociceptive action of ketoprofen in rats. Arch Med Res 32:13-20.

Donovan JL and DeVane CL (2001) A primer on caffeine pharmacology and its drug interactions in clinical psychopharmacology. Psychopharmacol Bull 35(3):30-48.

Fleiss JL (1981) Statistical methods for rates and proportions. 2nd edition. John Wiley and Sons, New York, 321 pp.

Fort DJ, Stover EL, Propst TL, Faulkner BC, Vollmuth TA and Murray FJ (1998) Evaluation of the developmental toxicity of caffeine and caffeine metabolites using the frog embryo teratogenesis assay - Xenopus (FETAX). Food Chem Toxicol 36:591-600.

Hepler PK and Bonsignore CL (1990) Caffeine inhibition of cytokinesis: ultrastructure of cell plate formation/degradation. Protoplasma 157:182-192. 
Hewavitharanage P, Karunaratne S and Kumar NS (1999) Effect of caffeine on shot-hole borer beetle (Xyleborus fornicatus) of tea (Camellia sinensis). Phytochemistry 51:35-41.

Higure Y and Nohmi M (2002) Repetitive application of caffeine sensitizes caffeine-induced $\mathrm{Ca}^{2+}$ release in bullfrog sympathetic ganglion neurons. Brain Res 954:141-150.

Itoyama MM and Bicudo HEMC (1992) Effects of caffeine on fecundity, egg laying capacity, development time and longevity in Drosophila prosaltans. Rev Bras Genet 15:303-321.

Itoyama MM, Bicudo HEMC and Manzato AJ (1995) Effects of caffeine on mating frequency and pre-copulation and copulation durations in Drosophila prosaltans. Cytobios 83:245-248.

Itoyama MM, Bicudo HEMC and Cordeiro JA (1997) Effects of caffeine on mitotic index in Drosophila prosaltans (Diptera). Rev Bras Genet 20:655-658.

Itoyama MM, Bicudo HEMC and Manzato AJ (1998) The development of resistance to caffeine in Drosophila prosaltans: productivity and longevity after ten generations of treatment. Cytobios 96:81-93.

Jones BR and Brancoft HR (1986) Distribution and probable physiological role of esterases in reproductive, digestive and fat-body tissue of adult cotton boll weevil, Anthonomus grandis. Biochem Genet 24:499-508.

Johnson FM, Kanapi CG, Richardson RH, Wheeler MR and Stone WS (1966) An operational classification of Drosophila esterases for species comparison. Univ Texas Publ 6615:517532.

Kawano T and Simões LCG (1987) Morphogenetic effects of caffeine on Biomphalaria glabrata (Pulmonata, Planorbidae). Dev Biol 90(3):281-301.

Kunin D, Bloch RT, Terada Y, Rogan F, Smith BR and Amit Z (2001) Caffeine promotes an ethanol-induced conditioned taste aversion: a dose-dependent interaction. Exp Clin Psychopharmacol 9(3):326-333.

La Pena A, Puertas MJ and Merino F (1981) Bimeiosis induced by caffeine. Cromosoma 83(2):241-248.

Lima-Catelani ARA (1996) Padrão de esterases de Aedes aegypti e Aedes albopictus. PhD Thesis, Universidade Estadual Paulista, São José do Rio Preto.

MacPhee DG and Leyden MF (1985). Effects of caffeine on ultraviolet-induced base-repair substitution and frameshift mutagenesis in Salmonella. Mutat Res 143:1-3.

Macoris MLG, Camargo MF, Silva IG, Takaku L and Andrighetti MT (1995) Modificação da suscetibilidade de Aedes (Stegomyia) aegypti ao temephos. Rev Pat Trop 24:31-40.

Mane SD, Tompkins L and Richmond RC (1983) Male esterase 6 catalyzes the synthesis of a Sex pheromone in Drosophila melanogaster female. Science 222:419-421.

Mazzarri MB and Georghiou GP (1995) Characterization of resistance to organophosphate, carbamate, and pyrethroid insecticides in field populations of Aedes aegypti from Venezuela. J Am Mosq Control Assoc 11(3):315-322.

Mourya DT, Hemingway J and Leake CJ (1993) Changes in enzyme titres with age in four geographical strains of Aedes aegypti and their association with insecticide resistance. Med Vet Entomol 7:11-16.

Narayanan PK, Rudnick JM, Walthers EA and Crissman HÁ (1997) Modulation in cell cycle and cyclin B1 expression in irradiated HeLa cells and normal human skin fibroblasts treated with staurosporine and caffeine. Exp Cell Res 233:118-127.

Nehlig A (1999) Are we dependent upon coffee and caffeine? A review on human and animal data. Neurosci Biobehav Rev 23:563-576

Pazer HL and Swanson LA (1972) Modern methods for statistical analysis. Intext Educational Publishers, Sconton, Pennsylvania, $483 \mathrm{pp}$.

Perez-Mendoza J, Fabrick JÁ, Zhu KY and Baker JE (2000) Alterations in esterases are associated with malathion resistance in Hobrobracon hebetor (Hymenoptera: Braconidae). J Econ Entomol 93:31-37

Pollard I, Jabbour H and Mehrabani PA (1987) Effects of caffeine administered during pregnancy on fetal development and subsequent function in the adult rat: prolonged effects on a second generation. J Toxicol Environ Health 22:1-15.

Pons FW and Muller P (1990) Induction of frameshift mutations by caffeine in Escherichia coli K12. Mutagenesis 5(2):173-177.

Sasaki YF, Imanishi H, Ohta T and Shirasu Y (1989) Modifying effects of components of plant essence on the induction of sister-chromatid exchanges in cultured Chinese hamster ovary cells. Mutat Res 226:103-110.

Sehgal SS and Simões LCG (1976) Preliminary results on the effects of neurotropic drugs on Drosophila melanogaster. Ciênc e Cult 28(8):917-920.

Sehgal SS, Simões LCG and Jurand A (1977) Effects of caffeine on growth and metamorphosis of moth fly Telmatoscopus albipunctatus (Diptera, Psychodidae). Ent Exp Appl 21:174-181.

Shanmugavelu M, Baytan AR, Chesnut JD and Bonning BC (2000) A novel protein that binds juvenile hormone esterase in fat body tissue and pericardial cells of the tobacco hornworm Manduca Sexta L. J Biol Chem 275:1802-1806.

Sousa-Polezzi RC (2002) Resistência a inseticidas em Aedes aegypti: modificações nos padrões de esterases e ação do fenobarbital. PhD Thesis, Universidade Estadual Paulista, São José do Rio Preto.

Steiner WWM and Johnson WE (1973) Techniques for electrophoresis of Hawaiian Drosophila US - IBP. Island Ecosyst Tech Rep 30:1-21.

Tango JS (1971) Utilização industrial do café e dos seus subprodutos. B Inst Tecnol Alim - ITAL, n. 28, dez.

Targa HJ and Rodriguez MEG (1982) A quantitative analysis of the factors influencing the food intake of adult females of Musca domestica, and its importance for chemical mutagen studies. Rev Bras Genet 5:669-677.

Terasaka O and Niitsu T (1987) Unequal cell division and chromatin differentiation in pollen grain cells. I. Centrifugal, cold and caffeine treatments. Bot Mag Tokyo 100:205216.

Thompson M, Shotkoski F and Ffrench-Constant R (1993) Cloning and sequencing of the cyclodiene insecticide resistance gene from the yellow fever mosquito Aedes aegypti. Febs Lett 235:187-190.

Tian Y, Ishikawa H and Yamuchi T (2000) Analysis of cytogenetic and developmental effects on pre-implantation, mid-gestation and near-term mouse embryos after treatment with trichlorfon during zygote stage. Mutat Res 471(1-2):37-44.

Timson J (1977) Caffeine. Mutat Res 47:1-52. 
Titenko-Holland N, Windham G, Kolachana P, Reinisch F, Parvatham S, Osorio AM and Smith MT (1997) Genotoxicity of malathion in human lymphocytes assessed using the micronucleus assay in vitro and in vivo: a study of malathion-exposed workers. Mutat Res 388(1):85-95.

Topaktas M, Rencuzogullari E and Ila HB (1996) In vivo chromosomal aberrations in bone marrow cells of rats treated with Marshal. Mutat Res 371(3-4):259-264.

Vaughan A and Hemingway J (1995) Mosquito carboxylesterase Esto $2^{1}\left(\mathrm{~A}_{2}\right)$ : cloning and sequence of the full-length cDNA for a major insecticide resistance gene worldwide in the mosquito Culex quinquefasciatus. J Biol Chem 270(28):1744-1749.

Vaughan A, Rocheleau T and Ffrench-Constant R (1997) Sitedirected mutagenesis of an acetylcholinesterase gene from the yellow fever mosquito Aedes aegypti confers insecticide insensitivity. Exp Parasitol 87:237-244.

Vaughan A, Chadee DD and Ffrench-Constant R (1998) Biochemical monitoring of organophosphorus and carbamate insecticide resistance in Aedes aegypti mosquitoes from Trinidad. Med Vet Entomol 12:318-321.

Zar JH (1999) Biostatistical analysis. 4th edition. Prentice Hall, New Jersey, 663 pp.

Editor: André Luiz Paranhos Perondini 